\title{
Saussurea lappa induces G2-growth arrest and apoptosis in AGS gastric cancer cells.
}

Seong Gyu Ko ${ }^{\S,}$, Hwang-Phill Kim ${ }^{\S}$, Dong-Hoon $\operatorname{Jin}^{\varphi}$, Hyun-Su Bae ${ }^{\S}$, Sung Hoon Kim ${ }^{\Omega}$, Chong-Hyeong Park*, and Jung Weon Lee ${ }^{\S, \Psi, \#}$. "Department of Internal Medicine, Sangji University, College of Oriental Medicine, Wonju-Si, Kangwon Province, 220-130, ${ }^{\$}$ Dept of Physiology, College of Oriental Medicine, Kyunghee Univ., 'Dept Internal medicine, College of Oriental Medicine, Kyungwon Univ., ${ }^{\varphi}$ Department of Life Science, Sogang University, ${ }^{\Omega}$ Graduate School of East-West Medical Science, Kyunghee University, ${ }^{\S}$ Cancer Research Institute, ${ }^{\S}$ Departments of Tumor Biology, and ${ }^{\Psi}$ Molecular and Clinical Oncology, College of Medicine, Seoul National University, Seoul 110-799, Korea.

\#: To whom any correspondence is to be sent,

Tel: $82-2-3668-7030$

Fax: 82-2-766-4487

E-mail:jwl@snu.ac.kr

Key words: Saussurea lappa, apoptosis, gastric cancer, p53, growth arrest, ATM/ATR.

Running title: Saussurea lappa-mediated G2-arrest and apoptosis.

This study was supported in part by a fund from Ministry of Health and Welfare, Korea (to S G Ko) and in part by 2003 BK21 Project for Medicine, Dentistry, and Pharmacy (to J W Lee). 


\section{ABSRACT}

The molecular effects of Saussurea lappa extracts, a traditional medicine in Eastern Asia, on the fate of gastric carcinoma have not been understood. In this study, its cytostatic effects were examined using gastric AGS cancer cells. Its treatment resulted in apoptosis and G2-arrest in a dose- and time-dependent manner. The effects were attributed to the regulation of cyclins and pro-apoptotic molecules and suppression of anti-apoptotic molecules. Therefore, these results suggest that extracts of Saussurea lappa root may be a candidate to deal with gastric cancers either by traditional herbal therapy or by combinational therapy with conventional chemotherapy. 


\section{INTRODUCTION}

The dried root of Saussurea lappa Clarke has been traditionally used for abdominal pain and tenesmus as a traditional medicine in Korea, China, and Japan. Sesquiterpene lactones including costunolide and dehydrocostus lactone are major components of the root and have been suggested to possess various biological activities, including anti-tumor, anti-ulcer, antiinflammatory, neurocytotoxic and cardiotonic activities [1]. Costunolide has been shown to have preventive effects on intestinal carcinogenesis, via pro-apoptotic effects of costunolide [2,3]. In addition, it has also been shown to inhibit endothelial cell proliferation via a blocking of VEGFR KDR/Flk-1 signal pathway [4].

Cell proliferation is a tightly controlled process consisting of multiple checkpoints responsible for the regulation of abnormal cell cycle progression. Transitions between G1, S, and $\mathrm{G} 2 / \mathrm{M}$ phases are regulated by biochemically-coordinated actions of cyclins, cyclindependent kinases (CDKs), CDK inhibitors (CKIs), all of which can in turn be modulated by diverse intracellular signals transduced from extracellular growth cues [5]. So far, the G1 to S phase transition through the restriction $(\mathrm{R})$ point or S phase entry has been shown to be regulated by mitogenic reagents, an intact cytoskeletal network, and cell adhesion as well [6-10]. In addition to the G1-checkpoint, there has been evidence that cellular systems often arrest at a G2-check point to avoid cell divisions that would produce daughters with damaged or abnormally synthesized DNA [11-13]. One of the molecules involved in the cell growth checkpoint includes $\mathrm{p} 53$, which induces cell cycle regulators including $\mathrm{p} 21^{\text {Waf1 }} \mathrm{CKI}$ [13]. In turn, p2 $1^{\text {Waf1 }} \mathrm{CKI}$ inhibits CDC2-cylinB complex, leading to a G2-arrest [12].

On the other hand, although gastric cancer occurs very frequently and Saussurea lappa extracts have been used as a traditional medicine in Asia, the molecular effects of Saussurea lappa extracts on cell proliferation or apoptosis have not been precisely and fully studied. Knowledge with regards to gastric cancer and medicinal herbs can probably have an ever 
greater impact on clinical management. In this study, we have tried to explore how Saussurea lappa extract influences the growth of AGS gastric cancer cells at the molecular level. We found that treatment with Saussurea lappa extract on AGS gastric cancer cells resulted in G2-growth arrest, presumably involving p53 and p21 Waf1 $\mathrm{CKI}$ induction and concomitant reduction of cyclin B1. Furthermore, the extracts induced apoptosis via activation of pro-apoptotic molecules including Bax and caspase3, and suppression of antiapoptotic $\mathrm{Bcl}_{2}$. 


\section{MATERIALS AND METHODS}

Preparation of Saussurea lappa extracts: The extract of Saussurea lappa root (BoKwang Crude Drugs Co., Seoul, Korea) was prepared by sonication in $80 \%$ ethanol and then a freezedrying process. The HPLC analysis of the extracts was performed using a standard material of costunolide (Wako Pure Chemicals Ind. Co., Japan), with Breeze ${ }^{\mathrm{TM}}$ HPLC systems with a Waters 2487 Dual Wavelength Absorbance Detector (Waters Corp., Milford, MA). Commercial pure costunolide $(0.5 \mathrm{mg} / \mathrm{ml}$ of acetone $)$ or test sample of the extracts $(10.0$ $\mathrm{mg} / \mathrm{ml}$ of acetone) were used in the HPLC analysis. The powder form of the extract was dissolved in RPMI 1640 medium (Life Technologies, Inc.) to $10 \mathrm{mg} / \mathrm{ml}$, vortexed at room temperature for $1 \mathrm{~min}$, and incubated at $37^{\circ} \mathrm{C}$ for $1 \mathrm{hr}$ while rotating before use. This solution was centrifuged at 12,000 rpm for $5 \mathrm{~min}$ to remove any insoluble ingredients. The supernatant was passed through a $0.22 \mu \mathrm{m}$ filter for sterilization and diluted with RPMI 1640 culture medium to final concentrations of $6.25 \sim 1,000 \mu \mathrm{g} / \mathrm{ml}$.

Cell Culture: A human gastric cancer cell line (AGS) purchased from ATCC or a normal epithelial cell line from rat intestine (RIE1), were grown in RPMI 1640 or DMEM-high glucose (Life Technologies, Inc., Rockville, MD) containing 10\% FBS (Hyclone Laboratories, Inc., Logan, UT) and $1 \%$ gentamicin in a $5 \% \mathrm{CO}_{2}$ humidified atmosphere. Subconfluent monolayers of cells were used in all experiments.

Growth Inhibition Assay: To determine the inhibition effect of Saussurea lappa extract on proliferation of cells, cell viability was analyzed by measuring MTT dye absorbance of viable cells in the absence or presence of Saussurea lappa extract. Ten thousand cells per well were seeded into 96-well plates (Nunc, Roskilde, Denmark) for $24 \mathrm{~h}$, treated with various concentrations of Saussurea lappa extract, and incubated for 3 days at $37^{\circ} \mathrm{C}$. Subsequently, $50 \mu \mathrm{l}$ of MTT (Sigma) at a concentration of $2 \mathrm{mg} / \mathrm{ml}$ was added to each well, and cells were incubated for an additional $4 \mathrm{~h}$ at $37^{\circ} \mathrm{C}$. The supernatant was aspirated, $150 \mu \mathrm{l}$ of DMSO 
was then added to the wells, and then absorbance at a wavelength of $570 \mathrm{~nm}$ was measured using an ELX800 microplate reader (Bio-Tek Instruments, Inc., Winooski, VT). The $\mathrm{IC}_{50}$ was calculated, by setting the viability of untreated cells at $100 \%$, expecting that cell death in control cells would be negligible. To examine cytostatic effects by the extracts, cells in two sets were treated with either 80 or $100 \mu \mathrm{g} / \mathrm{ml}$ for $48 \mathrm{~h}$, and then one set at each extract concentration was replaced with normal culture media and the other set was continuously kept in the extract-containing condition. At the various times, cell viability was measured by a MTT assay explained above.

Annexin V staining: Cells were untreated or treated with Saussurea lappa extract for $48 \mathrm{~h}$ at $100 \mu \mathrm{g} / \mathrm{ml}$, prior to flow cytometric determination, as explained previously [14].

Flow Cytometric Cell Cycle or DNA Content Analysis: A total of $5 \times 10^{5}$ cells were seeded in $60 \mathrm{~mm}$ dishes and incubated for $24 \mathrm{~h}$ at $37^{\circ} \mathrm{C}$. Saussurea lappa extract at the various concentrations indicated was directly added to the dishes and incubated for an additional 24, 48, or 72 hrs. After the incubation, both detached (probably apoptotic) and adherent cells were combined, fixed by addition of $4 \mathrm{ml}$ of $70 \%$ ethanol, and stored at $-20^{\circ} \mathrm{C}$ for at least 30 min. Cells were then pelletted, washed twice with ice-cold PBS, incubated in PBS containing $10 \mu \mathrm{g} / \mathrm{ml}$ of RNase A (Sigma) for $15 \mathrm{~min}$ at $37^{\circ} \mathrm{C}$, and stained with $10 \mu \mathrm{g} / \mathrm{ml}$ of propidium iodide (PI). The relative DNA content per cell of the samples was obtained by measuring the fluorescence of PI that bound stoichiometrically to DNA. The cell cycle was analyzed using a FACStar flow cytometer (Becton Dickinson, San Jose, CA) and a ModFit LT V2.0 software.

Western Blot Analysis: AGS cells in $100 \mathrm{~mm}$ dishes were treated with or without Saussurea lappa extract for indicated periods. In certain cases, cells were pretreated with $5 \mathrm{mM}$ Caffeine (Sigma) 20 min before the extract treatments. After the incubation, the cells were washed with ice-cold PBS and lysates were prepared by using a lysis buffer containing 20 
$\mathrm{mM}$ Tris- $\mathrm{Cl}$ ( $\mathrm{pH} 7.4), 100 \mathrm{mM} \mathrm{NaCl}, 1 \% \mathrm{NP} 40,0.5 \%$ sodium deoxycholate, $5 \mathrm{mM} \mathrm{MgCl}$, $0.1 \mathrm{mM}$ phenylmethylsulfonyl fluoride, $0.1 \mathrm{mM}$ pepstatin $\mathrm{A}, 0.1 \mathrm{mM}$ antipain, $0.1 \mathrm{mM}$ chymostatin, $0.2 \mathrm{mM}$ leupeptin, $10 \mu \mathrm{g} / \mathrm{ml}$ aprotinin, $0.5 \mathrm{mg} / \mathrm{ml}$ soybean trypsin inhibitor, and $1 \mathrm{mM}$ benzamidine. After incubating the lysates on ice for $30 \mathrm{~min}$, whole cell extracts were cleared by centrifugation at $13,000 \mathrm{rpm}$ for $20 \mathrm{~min}$. Twenty $\mu \mathrm{g}$ of protein were resolved by SDS-PAGE denaturing gels and transferred onto a nitrocellulose membrane. The membrane was blocked for $1 \mathrm{~h}$ in $20 \mathrm{mM}$ Tris-buffered saline (TBS) buffer containing 5\% skim milk and $0.1 \%$ Tween 20 and then probed with specific antibodies for the indicated molecules. Antibodies against p53, cyclins D1, E, A, and B1, Cdc2, p21, and caspase 3 were purchased from Santa Cruz Biotechnology, Inc. (Santa Cruz, CA) and anti-active caspase 3 was from Promega (Madison, WI). The protein was visualized by using an ECL chemiluminescence method (Amersham Pharmacia Biotech), followed by autoradiography. 


\section{RESULTS}

We have had an interest in examining the anticancer activity of Saussurea lappa extract on a gastric cancer cell line, AGS cells, with a special emphasis on the effects of the extract on apoptosis and cell cycle arrest pathway.

We first checked whether the Saussurea lappa extracts included Sesquiterpene lactones including costunolide by a HPLC analysis. As shown in the figure $1 \mathrm{~A}$, the extracts showed major peaks including one for costunolide. Then we determined how Saussurea lappa extract affected the viability of AGS cells, by quantitating the viable cells after treating cells with various concentrations ranging from $10 \mu \mathrm{g} / \mathrm{ml}$ to $1 \mathrm{mg} / \mathrm{ml}$ using the MTT assay. When cell viability was determined after treatment with Saussurea lappa extract for 3 days, there was a dose-dependent inhibition of cell viability, and most cells were not vital at 500 $\mu \mathrm{g} / \mathrm{ml}$ of extract. The apparent $\mathrm{IC}_{50}$ was determined to be $70 \mu \mathrm{g} / \mathrm{ml}$ (Figure 1B). Meanwhile, the parallel treatment of the extracts to a normal epithelial cell line from rat intestine (RIE1) showed much less strong effects on inhibition of viability (with an IC50 at about $500 \mu \mathrm{g} / \mathrm{ml}$, Figure 1B). Therefore, Saussurea lappa extract could induce growth inhibition of gastric cancer cells such as AGS cells, in addition to other type cancer cells previously reported including intestinal carcinoma cells [3] and leukemia [15]. Next we tried to examine whether the growth inhibitory effects were cytotoxic or cytostatic. Cells in two sets were treated with either 80 or $100 \mu \mathrm{g} / \mathrm{ml}$ Saussurea lappa for $48 \mathrm{~h}$, and then the extract-containing media of one set in each extract concentration was replaced with fresh normal culture media before additional $48 \mathrm{~h}$ incubation. When viability in various conditions was analyzed with the MTT assay, the extract-retracted conditions showed recoveries of viability as time passed after the replacements of media, meanwhile the extractcontaining conditions kept growth inhibition (Figure 1C). These indicate the cytostatic effects by the Saussurea lappa extract. 
Next we tried to determine if Saussurea lappa extract induced apoptotic cell death of AGS cells. Flow cytometric measurements of cells with sub G1 DNA content were performed at various times after treatment with $100 \mu \mathrm{g} / \mathrm{ml}$ Saussurea lappa extract. As shown in figure $2 \mathrm{~A}$, untreated cells did not show any significant apoptosis, whereas cells were becoming rapidly apoptotic with time after treatment with the extract. When cells were treated with $100 \mu \mathrm{g} / \mathrm{ml}$ Saussurea lappa extract for $48 \mathrm{~h}$, about $42 \%$ cells were apoptotic. In addition, from another approach to detect apoptotic cells using annexin $\mathrm{V}$ staining, an apoptotic population of about $37 \%$ was obvious under the same treatment condition (Figure 2B). A difference in the sensitivity of the two methods using different reagents presumably with different antigen- or binding partner- binding affinities is likely to account for the discrepancy in the percentage of apoptotic cells. Interestingly, under Saussurea lappa extract treatment conditions, more cells were in the $\mathrm{G} 2 / \mathrm{M}$ cell cycle phase than in the untreated control, indicating that treatment with Saussurea lappa extract involved G2/M arrest, probably before apoptosis (Figure 2A). Therefore, we analyzed the cell cycle phase of adherent cells after treatment with Saussurea lappa extract (i.e., cells with non-subG1 DNA contents) at different time points. Compared to the untreated control, cells in the G1 phase was clearly reduced over time, whereas cells in the S phase was gradually increased until $24 \mathrm{~h}$ after the treatment and then declined notably at $48 \mathrm{~h}$ treatment (Figure 2C). However, a predominant population in the G2/M cell cycle phase was evident 48 hrs after treatment with Saussurea lappa extract, indicating that cells were undergoing G2-arrest by this treatment (Figure 2C). The G2-arrest induced by Saussurea lappa extract was confirmed by another approach, where the expression levels of cyclins after treatment with Saussurea lappa extract was measured biochemically. As shown in figure 3, levels of cyclin D1 did not decrease and cyclins $\mathrm{E}$ and A rather increased with the treatment until $24 \mathrm{~h}$ after the treatment, indicating that G1-arrest did not occur and progression to and through S phase occurred until the $24 \mathrm{~h}$ 
posttreatment as shown in figure $2 \mathrm{C}$. In addition, the increases in cyclins $\mathrm{E}$ and $\mathrm{A}$ were not correlated with an increase in mitotic cyclin B, which indicates that mitosis could not occur. However, at $48 \mathrm{~h}$ after the treatment, the cyclins $\mathrm{E}$ and $\mathrm{A}$ were declined and cyclin B was not detected, indicating that G2 arrest and apoptosis might simultaneously occurred (Figures 3 and 2). These indicate that $\mathrm{S}$ phase progression occurred until $24 \mathrm{hr}$ posttreatment or so, but that cells are either in G2 arrest and/or death by apoptotic DNA degradation at $48 \mathrm{~h}$.

Previously it was shown that p53 activation and thus induction of $\mathrm{p} 21^{\text {Waf1 }} \mathrm{CKI}$ is involved in G1 and G2-arrest as well in response to DNA damage. Therefore, we have tried to examine whether both $\mathrm{p} 53$ and $\mathrm{p} 21^{\text {Waf1 }} \mathrm{CKI}$ might be induced by Saussurea lappa treatment. When levels of the both were biochemically measured, it was clear that $\mathrm{p} 53$ and p2 $1^{\text {Wafl }}$ CKI increased by treatment with Saussurea lappa extract at time points that were coincident with the induction of apoptosis (Figure 4A and 2A). Therefore, Saussurea lappa extract might lead to activation of p53 and then induction of $\mathrm{p} 21^{\text {Wafl }} \mathrm{CKI}$, resulting in G2arrest and apoptosis.

G2 arrest is also known to be mediated by ataxia- telangiectasia mutated (ATM) and ATM and Rad3-related kinase (ATR), which are induced by DNA damages and inactivate mitotic CDK (Cdc2) by Chk1/2-activation-mediated retaining of its stimulator $\mathrm{Cdc} 25 \mathrm{C}$ at cytoplasm. ATM/ATR can also phosphorylate Ser15 of and activate p53 (reviewed in [16]. To check whether the G2 arrest by the extracts was dependent on ATM/ATR-dependent pathways, we have checked effects of caffeine, an ATM/ATR inhibitor, on regulation of the cell cycle regulators expression by the Saussurea lappa extract treatment. When cells were treated only with the Saussurea lappa extract, the expression and phosphorylation at Ser15 of p53 was increased but $\mathrm{Cdc} 2$ and $\mathrm{Cdc} 25 \mathrm{C}$ decreased (Figure 4A and B). Meanwhile, in the presence of ATM/ATR inhibition by caffeine, the extract treatment abolished in part the Saussurea lappa extract-mediated effects (Figure 4B). However, the caffeine-independent 
effects were obvious at $12 \mathrm{~h}$ after the extract treatment, compared to control (i.e., untreated with the Saussurea lappa extract). These indicate that the Saussurea lappa extract treatment resulted in G2 arrest and apoptosis probably via ATM/ATR-dependent and -independent pathways involving increase in and activation of $\mathrm{p} 53$.

When we next checked levels of certain pro-apoptotic or anti-apoptotic molecules, their levels correlated well with the apoptotic trend of AGS cells induced by treatment with Saussurea lappa extract. That is, the expression level of anti-apoptotic molecules, such as $\mathrm{Bcl}_{2}$, decreased gradually, whereas a pro-apoptotic molecule such as Bax, which opposes the action of $\mathrm{Bcl}_{2}$, increased by treatment with the extract (Figure 5). Furthermore, cleavage of procaspase 3 , activation of caspase 3 , and loss of intact poly(ADP-ribose) polymerase (PARP) were obvious, although we failed to detect the cleaved products of caspase 3 and PARP, probably due to extensive apoptosis leading to degradation of their cleaved products (Figure 5), indicating that thereby their activation could lead to apoptosis.

Taken together, the extract from Saussurea lappa, an herbal medicine frequently used in Eastern Asia, has been shown here to induce the G2-arrest of AGS gastric cancer cells probably by modulating cyclin levels through $\mathrm{p} 53 / \mathrm{p} 21^{\text {Wafl }} \mathrm{CKI}$ induction. The extract also induced concomitant programmed cell death by activating pro-apoptotic molecules and suppressing anti-apoptotic molecules. These results indicate that Saussurea lappa extract can be a candidate therapeutic reagent against gastric cancer. 


\section{DISCUSSION}

We observed that treatment of Saussurea lappa extract induced G2-arrest and apoptosis of AGS gastric cancer cells, probably by both ATM/ATR-dependent and independent pathways involving induction of $\mathrm{p} 53 / \mathrm{p} 21^{\text {Waf1 }} \mathrm{CKI}$, induction and activation of pro-apoptotic molecules, and concomitantly suppression of anti-apoptotic molecules. Meanwhile, the extract caused much less significant cytostatic effects on normal rat intestinal epithelial RIE1 cells, indicating tumor cell specific effects. These results may suggest Saussurea lappa extracts as a candidate for anti-tumor therapeutic reagent.

Cell cycle checkpoints are available to allow cellular repair when cells incur damage, including DNA damage, as well as to dissipate exogenous cellular stress signals, and to look for extracellular growth factors. In most cases, checkpoints may result in the activation of programmed cell death (apoptosis) signaling, if the cellular damages are too serious to be properly repaired. Therefore, defects in cell cycle checkpoints and apoptosis would results in tumorigenesis [17]. We observed in the cell cycle analysis that treatment of Saussurea lappa extract resulted in apoptosis and G2/M-arrest as well. Consistently, we also observed that a consistent cyclin D1 level around cell cycles, that cyclins E and A increased until $24 \mathrm{~h}$, although they gradually declined afterward (to $48 \mathrm{~h}$ ), and that mitotic cyclin B1 was decreased by the extract treatment, indicating a progression to S-phase cell cycle before eventual G2/M phase arrest and apoptosis. These indicate that $\mathrm{S}$ phase progression occurred until $24 \mathrm{hr}$ after the treatment or so, and cells are either in G2 arrest and/or death by apoptotic DNA degradation at $48 \mathrm{~h}$.

It was also shown that the extract treatment resulted in the induction of $\mathrm{p} 53$ and $\mathrm{p} 21^{\text {Waf } 1}$ CKI (Figure 4A and B), which are known to be important for G1-arrest as well as G2-arrest. In addition, the extract-induced increases in p53 level and its Ser15 phosphorylation were blocked in part by an ATM/ATR inhibitor, caffeine. Meanwhile, the decreases in Cdc2 and 
Cdc25C on the extract treatment were attenuated by ATM/ATR inhibition (Figure 4B). However, ATM/ATR inhibition could not completely abolish the extract-mediated increases in p53 and its Ser15 phosphorylation (e.g., control versus $12 \mathrm{~h}$ treatment).

Previously, it was reported that p53 protein induced cell cycle regulators including p21 ${ }^{\text {Wafl }}$ CKI [13], which in turn initially inhibits the Cdc2-cylinB1 complex and subsequently reduces the cyclin $\mathrm{B} 1$ and $\mathrm{Cdc} 2$ protein levels, leading to $\mathrm{G} 2$-arrest $[12,18]$. In addition to these mechanisms involving $\mathrm{p} 21^{\text {Waf1 }} \mathrm{CKI}$, p53-dependent $\mathrm{G} 2$ arrest involves transcriptional up-regulation of additional downstream targets including 14-3-3 $\sigma$, which modulates the subcellular localization of the cyclin B1/Cdc2 complex [19] and GADD45 [20]. In other words, p53 contributes to a sustained G2-arrest through cyclin B1/Cdc2 inhibition by colocalizing the complex with either nuclear $\mathrm{p} 21^{\text {Waf1 }} \mathrm{CKI}$ or cytoplasmic 14-3-3 $\sigma$. Meanwhile, ATM/ATR can cause G2 arrest via p53- independent and dependent manners. ATM/ATR can be induced by DNA damages and inactivate mitotic CDK (Cdc2) by Chk1/2-activationmediated retaining of its stimulator $\mathrm{Cdc} 25 \mathrm{C}$ at cytoplasm. ATM/ATR can also phosphorylated Ser15 of and activate p53 (reviewed in [16]. Therefore, observations from this current study and previous studies indicate that the Saussurea lappa-induced G2 arrest might involve ATM/ATR- dependent and independent pathways.

In addition to arresting cells at the G2-phase, treating cells with Saussurea lappa extract induced significant apoptosis over time after the treatment. Currently, it is not clear whether or not treatment of cells with Saussurea lappa extract might trigger the death signal through cell membrane-based receptors. However, it is clear that apoptosis mediated by the treatment involves activation of caspase(s), as we observed the loss of intact procaspase 3 and activation of caspase 3 (Figure 5). We also observed an alteration in the levels of $\mathrm{Bcl}_{2}$ and Bax proteins. It is well-known that $\mathrm{Bcl}_{2}$ and $\mathrm{Bax}$ family members have opposing actions, thereby regulating the activation of caspases [21]. p53 can regulate the induction of the both 
pro- and anti-apoptotic factors [22,23]. $\mathrm{Bcl}_{2}$ is anti-apoptotic and down-regulated by $\mathrm{p} 53$, whereas Bax is pro-apoptotic and induced by p53 [24-26]. Bax facilitates the release of the apoptosis-inducing factor and cytochrome $c$ from the mitochondria, leading to the activation of the caspase cascade [27]. Once caspases are activated, various cellular proteins, including PARP, are cleaved by their actions, leading to defects in their signaling and/or structural functions, thereby resulting in cell death [28]. In this current study, such a signaling mechanism appears to be taking place with regard to the induction of p53 and Bax, a corresponding reduction in $\mathrm{Bcl}_{2}$ expression, and activation of caspase 3 , thereby leading to apoptosis. Therefore, the cytostatic effects of Saussurea lappa extract appear to involve a G2-arrest and apoptosis, probably via induction of $\mathrm{p} 53$.

The G2 checkpoint control mediated via ATM/ATR-dependent or -independent pathways involving p53 and eventual apoptosis are potentially important determinants of tumor sensitivity to DNA damage. Previously it has been demonstrated in many studies that when cells were exposed to a combination of DNA damaging agents and checkpoint-inhibitory drugs, p53 is inactivated and the G2 checkpoint control is relaxed, leading to enhanced cytostatic effects. This suggests the possibility that such a combination could be used therapeutically to target tumor cells specifically, since p53 function is compromised or absent in many human tumors including gastric cancer [29]. Therefore, observations from studies including this current one may have important clinical implications for a medicinal herbal therapy approach to take care of gastric cancers with fewer side effects on normal epithelial cells. In addition, a combining conventional chemotherapy with traditional medicinal herbs, such as Saussurea lappa extract, may be an effective way to treat gastric cancers. 


\section{REFERENCES}

[1] M Robles, M Aregullin, J West, E Rodriguez: Recent studies on the zoopharmacognosy, pharmacology and neurotoxicology of sesquiterpene lactones. Planta Med. 61 (1995) 199-203.

[2] MG Lee, KT Lee, SG Chi, JH Park: Costunolide induces apoptosis by ROS-mediated mitochondrial permeability transition and cytochrome $\mathrm{C}$ release. Biol. Pharm. Bull. 24 (2001) 303-306.

[3] H Mori, T Kawamori, T Tanaka, M Ohnishi, J Yamahara: Chemopreventive effect of costunolide, a constituent of oriental medicine, on azoxymethane-induced intestinal carcinogenesis in rats. Cancer Lett. 83 (1994) 171-175.

[4] SJ Jeong, T Itokawa, M Shibuya, M Kuwano, M Ono, R Higuchi, T Miyamoto: Costunolide, a sesquiterpene lactone from Saussurea lappa, inhibits the VEGFR KDR/Flk-1 signaling pathway. Cancer Lett. 187 (2002) 129-133.

[5] AJ Obaya, JM Sedivy: Regulation of cyclin-Cdk activity in mammalian cells. Cell Mol.Life Sci. 59 (2002) 126-142.

[6] RK Assoian, X Zhu: Cell anchorage and the cytoskeleton as partners in growth factor dependent cell cycle progression. Curr. Opin. Cell Biol. 9 (1997) 93-98.

[7] RK Assoian, MA Schwartz: Coordinate signaling by integrins and receptor tyrosine kinases in the regulation of G1 phase cell-cycle progression. Curr. Opin. Genet. Dev. 11 (2001) 48-53.

[8] EH Danen, KM Yamada: Fibronectin, integrins, and growth control. J. Cell Physiol. 189 (2001) 1-13.

[9] RL Juliano: Signal transduction by cell adhesion receptors and the cytoskeleton: Functions of Integrins, Cadherins, Selectins, and Immunoglobulin-Superfamily Members. Annu. Rev. Pharmacol. Toxicol. 42 (2002) 283-323.

[10] S Huang, DE Ingber: A discrete cell cycle checkpoint in late G(1) that is cytoskeletondependent and MAP kinase (Erk)-independent. Exp. Cell Res. 275 (2002) 255-264.

[11] AB Niculescu, 3rd, X Chen, M Smeets, L Hengst, C Prives, SI Reed: Effects of p21(Cip1/Waf1) at both the G1/S and the G2/M cell cycle transitions: pRb is a critical determinant in blocking DNA replication and in preventing endoreduplication. Mol. Cell Biol. 18 (1998) 629-643.

[12] VA Smits, R Klompmaker, T Vallenius, G Rijksen, TP Makela, RH Medema: p21 inhibits Thr161 phosphorylation of Cdc2 to enforce the G2 DNA damage checkpoint. J. Biol. Chem. 275 (2000) 30638-30643.

[13] F Bunz, A Dutriaux, C Lengauer, T Waldman, S Zhou, JP Brown, JM Sedivy, KW Kinzler, B Vogelstein: Requirement for p53 and p21 to sustain G2 arrest after DNA damage. Science 282 (1998) 1497-1501.

[14] JW Lee, RL Juliano: alpha5beta1 integrin protects intestinal epithelial cells from apoptosis through a phosphatidylinositol 3-kinase and protein kinase B- dependent pathway. Mol. Biol. Cell 11 (2000) 1973-1987.

[15] JH Choi, J Ha, JH Park, JY Lee, YS Lee, HJ Park, JW Choi, Y Masuda, K Nakaya, KT Lee: Costunolide triggers apoptosis in human leukemia U937 cells by depleting intracellular thiols. Jpn. J. Cancer Res. 93 (2002) 1327-1333.

[16] AA Goodarzi, WD Block, SP Lees-Miller: The role of ATM and ATR in DNA damage-induced cell cycle control. Prog. Cell Cycle Res. 5 (2003) 393-411.

[17] JA Pietenpol, ZA Stewart: Cell cycle checkpoint signaling: cell cycle arrest versus apoptosis. Toxicology 181-182 (2002) 475-481.

[18] SA Innocente, JL Abrahamson, JP Cogswell, JM Lee: p53 regulates a G2 checkpoint through cyclin B1. Proc. Natl. Acad. Sci. U S A 96 (1999) 2147-2152. 
[19] TA Chan, H Hermeking, C Lengauer, KW Kinzler, B Vogelstein: 14-3-3Sigma is required to prevent mitotic catastrophe after DNA damage. Nature 401 (1999) 616-20.

[20] XW Wang, Q Zhan, JD Coursen, MA Khan, HU Kontny, L Yu, MC Hollander, PM O'Connor, AJ Fornace, Jr., CC Harris: GADD45 induction of a G2/M cell cycle checkpoint. Proc. Natl. Acad. Sci. U S A 96 (1999) 3706-3711.

[21] TW Sedlak, ZN Oltvai, E Yang, K Wang, LH Boise, CB Thompson, SJ Korsmeyer: Multiple Bcl-2 family members demonstrate selective dimerizations with Bax. Proc. Natl. Acad. Sci. U S A 92 (1995) 7834-7838.

[22] A Basu, S Haldar: The relationship between BcI2, Bax and p53: consequences for cell cycle progression and cell death. Mol. Hum. Reprod. 4 (1998) 1099-1109.

[23] C Brambilla, F Fievet, M Jeanmart, F de Fraipont, S Lantuejoul, V Frappat, G Ferretti, PY Brichon, D Moro-Sibilot: Early detection of lung cancer: role of biomarkers. Eur. Respir. J. Suppl. 39 (2003) 36s-44s.

[24] T Miyashita, S Krajewski, M Krajewska, HG Wang, HK Lin, DA Liebermann, B Hoffman, JC Reed: Tumor suppressor p53 is a regulator of bcl-2 and bax gene expression in vitro and in vivo. Oncogene 9 (1994) 1799-1805.

[25] T Miyashita, M Harigai, M Hanada, JC Reed: Identification of a p53-dependent negative response element in the bcl-2 gene. Cancer Res. 54 (1994) 3131-3135.

[26] T Miyashita, JC Reed: Tumor suppressor p53 is a direct transcriptional activator of the human bax gene. Cell 80 (1995) 293-299.

[27] RV Sionov, Y Haupt: The cellular response to p53: the decision between life and death. Oncogene 18 (1999) 6145-6157.

[28] AA Philchenkov: Caspases as regulators of apoptosis and other cell functions. Biochemistry (Mosc) 68 (2003) 365-376.

[29] MS Wu, CJ Chen, JT Lin: Genetic alterations and polymorphisms in gastric cancer. J. Formos. Med. Assoc. 102 (2003) 447-458. 


\section{FIGURE LEGENDS}

\section{Figure 1. Cytostatic effects by treatment of Saussurea lappa extract on gastric AGS cells.}

(A) HPLC histogram of the Saussurea lappa extract (lower) with a peak identical with one for a commercial Sesquiterpene lactone, costunolide. (B) Inhibition of AGS cell growth by the Saussurea lappa extract. AGS or RIE1 cells were seeded to wells of 96 well plates in the presence of normal culture media at $1.0 \times 10^{4}$ cells/well. Twenty four hours later, cells were treated with indicated concentrations of Saussurea lappa extract for additional $72 \mathrm{hrs}$. Then MTT assay was performed as explained in Material and methods. Data shown is representative from three independent experiments, in which each condition was in triplicate. Data were shown in mean \pm standard deviation (SD). (C) Recovery of cell growth from cytostatic effects of the Saussurea lappa extract via removal of the extracts. Cells were manipulated same as in (B). At $48 \mathrm{~h}$ after the extract treatment at 80 or $100 \mu \mathrm{g} / \mathrm{ml}$, the media of one set at each concentration (circles, $80 \mu \mathrm{g} / \mathrm{ml}$; squires, $100 \mu \mathrm{g} / \mathrm{ml}$ ) was replaced with normal culture media not including the extract (open circle or squire), whereas the other set was still keeping the extract (closed circle or squire) for additional $48 \mathrm{~h}$ incubation. At the various time indicated, cell viability was analyzed as explained in Materials and Methods.

Figure 2. Treatment of Saussurea lappa extract induced G2-arrest and apoptosis. (A) Saussurea lappa extract induced sub-G1 population. Cells in $60 \mathrm{~mm}$ culture dishes were treated with $100 \mu \mathrm{g} / \mathrm{ml}$ Saussurea lappa extracts for indicated periods. The treatment was done by a direct addition of Saussurea lappa extract solution into culture media. After incubation, cells floating and adherent were collected and combined before PI staining and flow cytometric analysis for DNA contents, as explained in the Materials and methods. Shown data are representative from three independent experiments. (B) Determination of apoptotic population via annexin V staining after Saussurea lappa treatment. Cells were 
untreated (left histogram) or treated (right histogram) with $100 \mu \mathrm{g} / \mathrm{ml}$ Saussurea lappa extracts for $48 \mathrm{~h}$, prior to flow cytometric quantitation of cells stained with annexin $\mathrm{V}$, as explained previously [14]. Data shown was representative from two independent analyses. (C) Cell cycle analysis by ModFit software was done using cells with non-subG1 DNA contents (i.e., normally DNA-containing population) in each condition; gating to include cell population with DNA content of $\mathrm{n}$ and $2 \mathrm{n}$ but not sub G1 was performed, prior to analysis of cell cycle population.

Figure 3. Treatment of Saussurea lappa extract regulates cyclins levels. Cells in $100 \mathrm{~mm}$ culture dishes were treated with $100 \mu \mathrm{g} / \mathrm{ml}$ Saussurea lappa extracts for indicated periods. After treatment, cells were washed twice with ice-cold PBS and then lysates were prepared using a RIPA lysis buffer. Lysates normalized to have equal protein amounts were used for immunoblots by SDS-PAGE using primary antibodies against the indicated molecules, as described in the Materials and methods. The data are representative of at least three isolated experiments.

Figure 4. Treatment of Saussurea lappa extract induces cell cycle control- dependent and independent on ATM/ATR pathways. Cells were treated with the Saussurea lappa extracts as explained above or with both $5 \mathrm{mM}$ caffeine and the extracts together. (A and B) Lysates were prepared as explained above and used for Western blots using primary antibodies against the indicated molecules. Data shown is representative from three independent observations.

Figure 5. Treatment of Saussurea lappa extract resulted in an increase or activation of pro-apoptotic molecules and a decrease of anti-apoptotic molecules. Lysates prepared as 
explained above were used for immunoblots using primary antibodies against the indicated molecules. Data shown are representative from at least 3 independent experiments. 
Figure 1. Seong Gyu Ko, et al

(A)
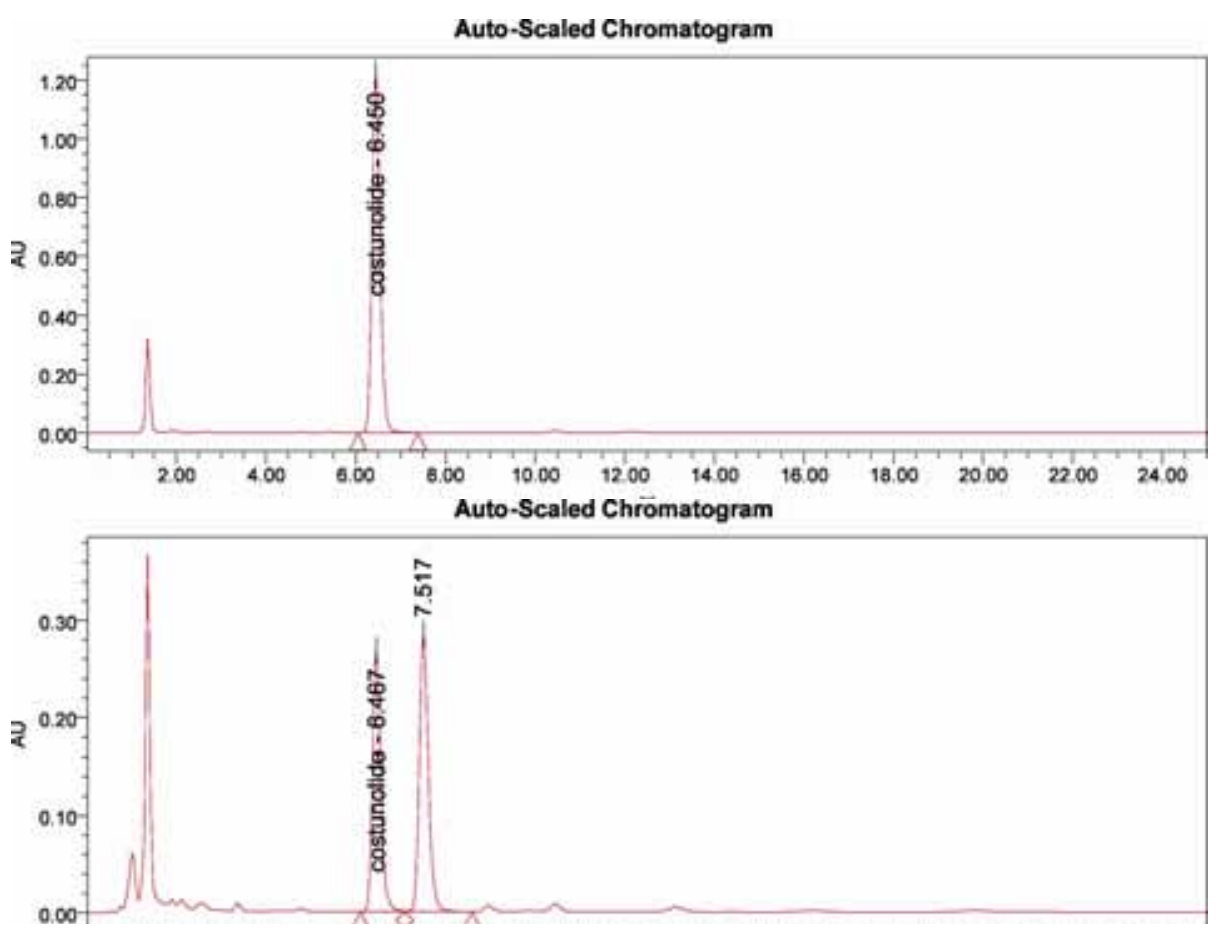

(B)

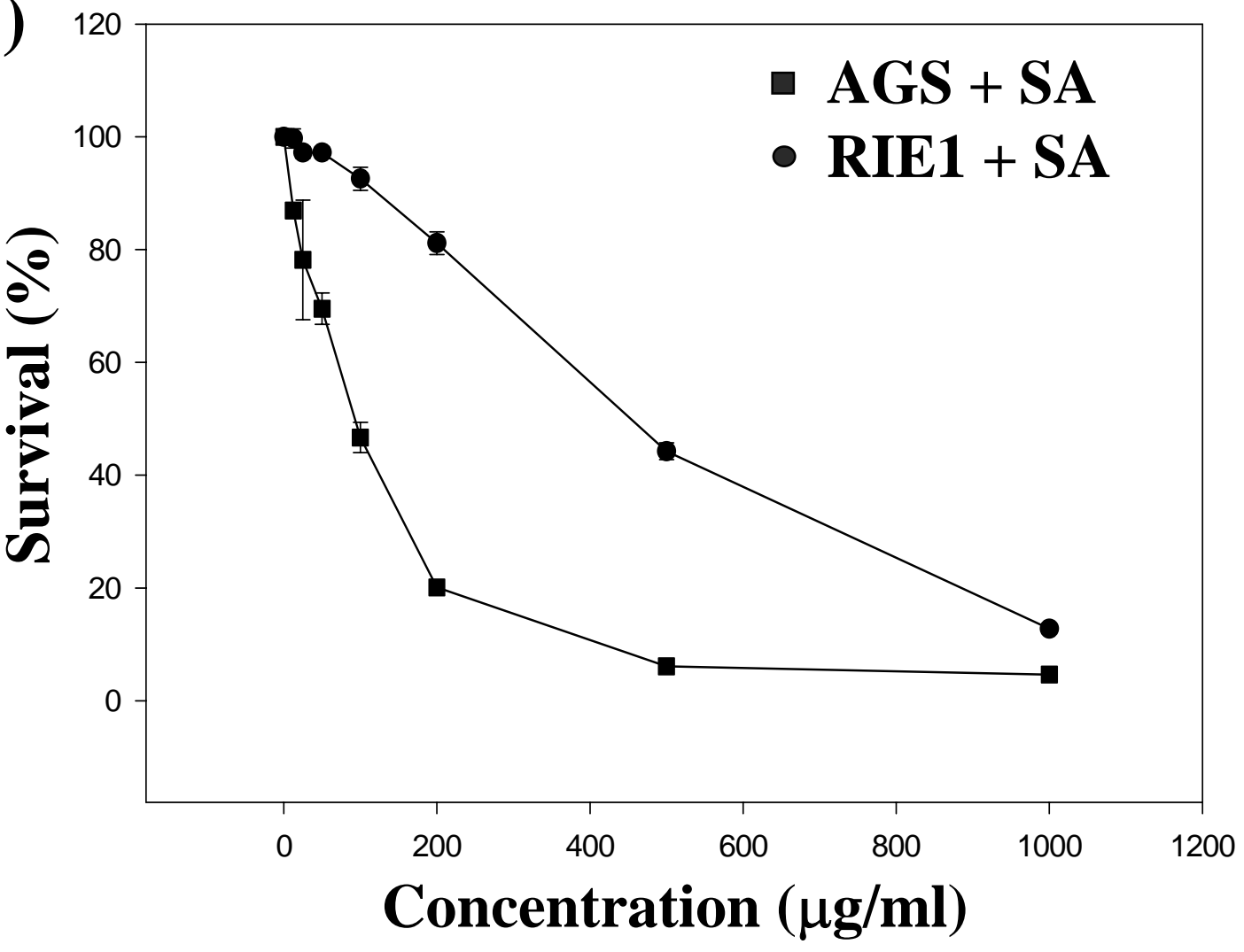


Figure 1. Seong Gyu Ko, et al

(C)

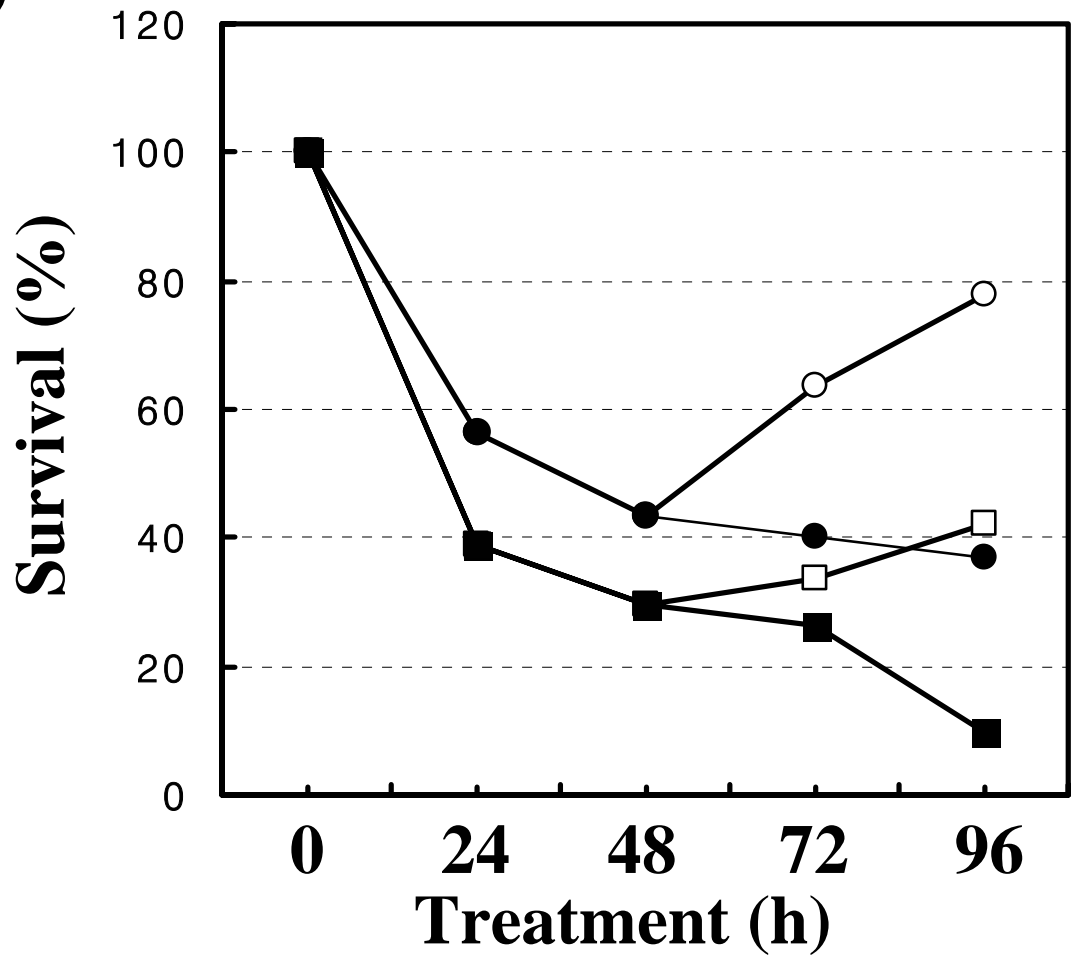


Figure 2. Seong Gyu Ko, et al

(A)

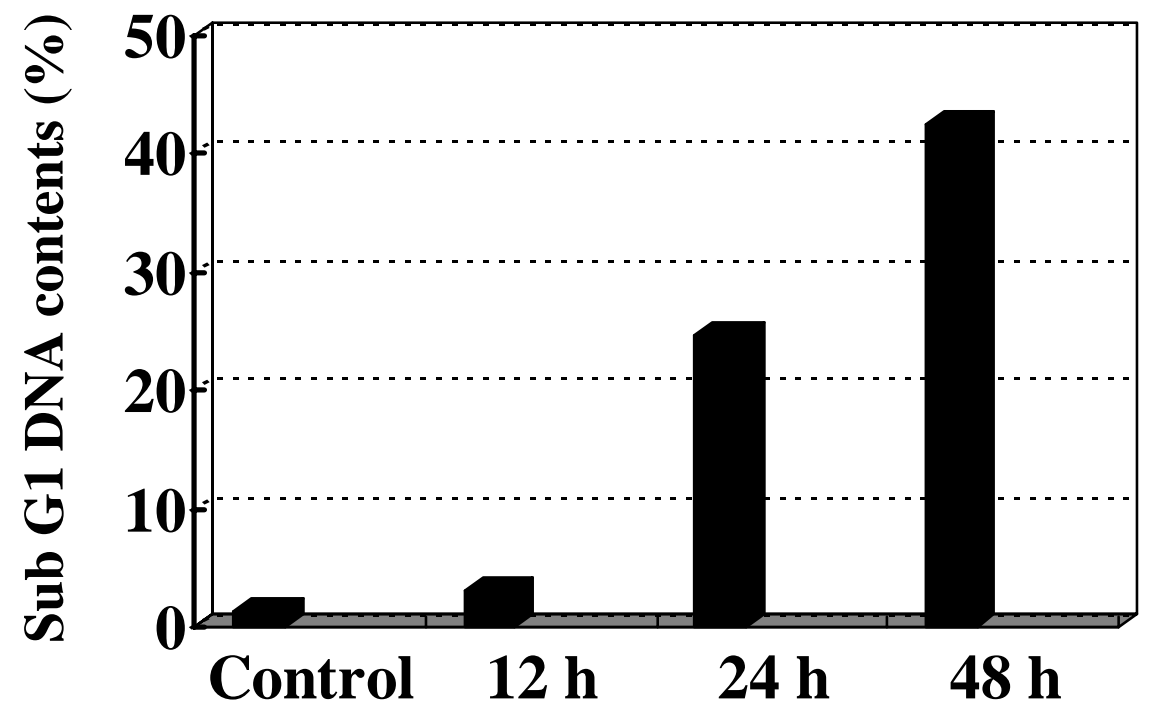

(B)
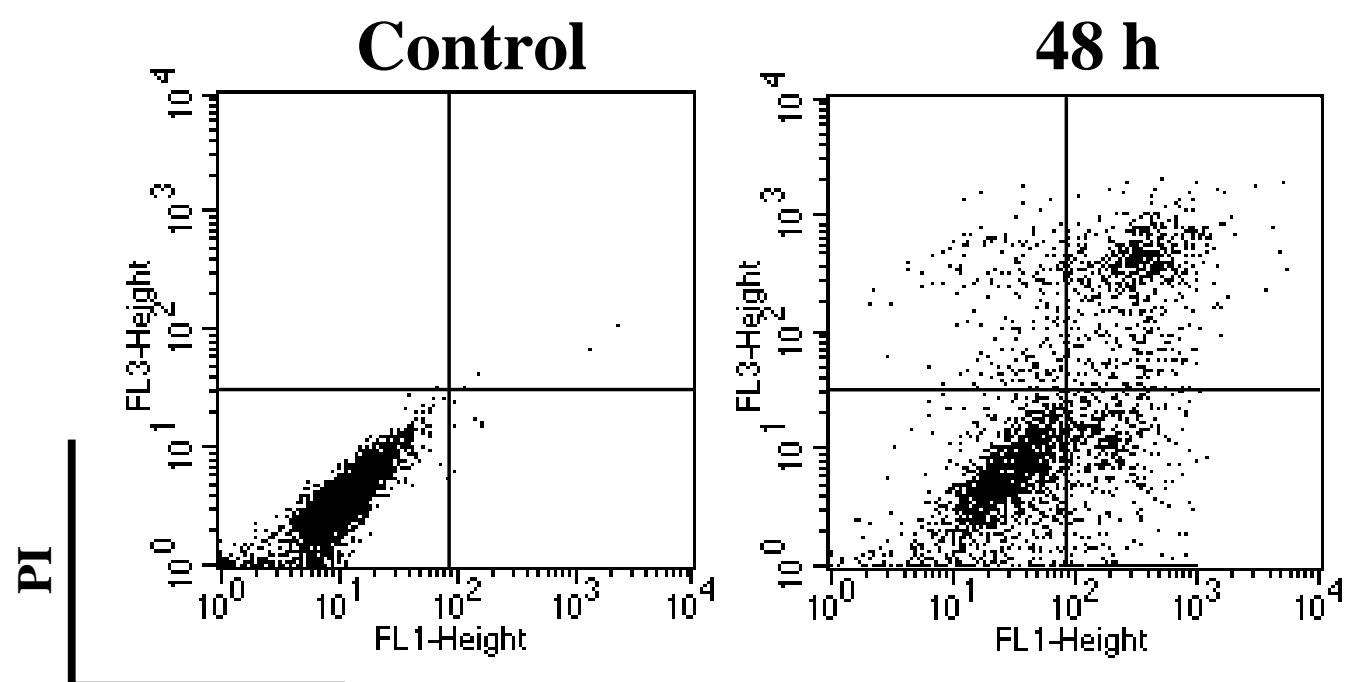

Annexin V-FITC 
Figure 2. Seong Gyu Ko, et al

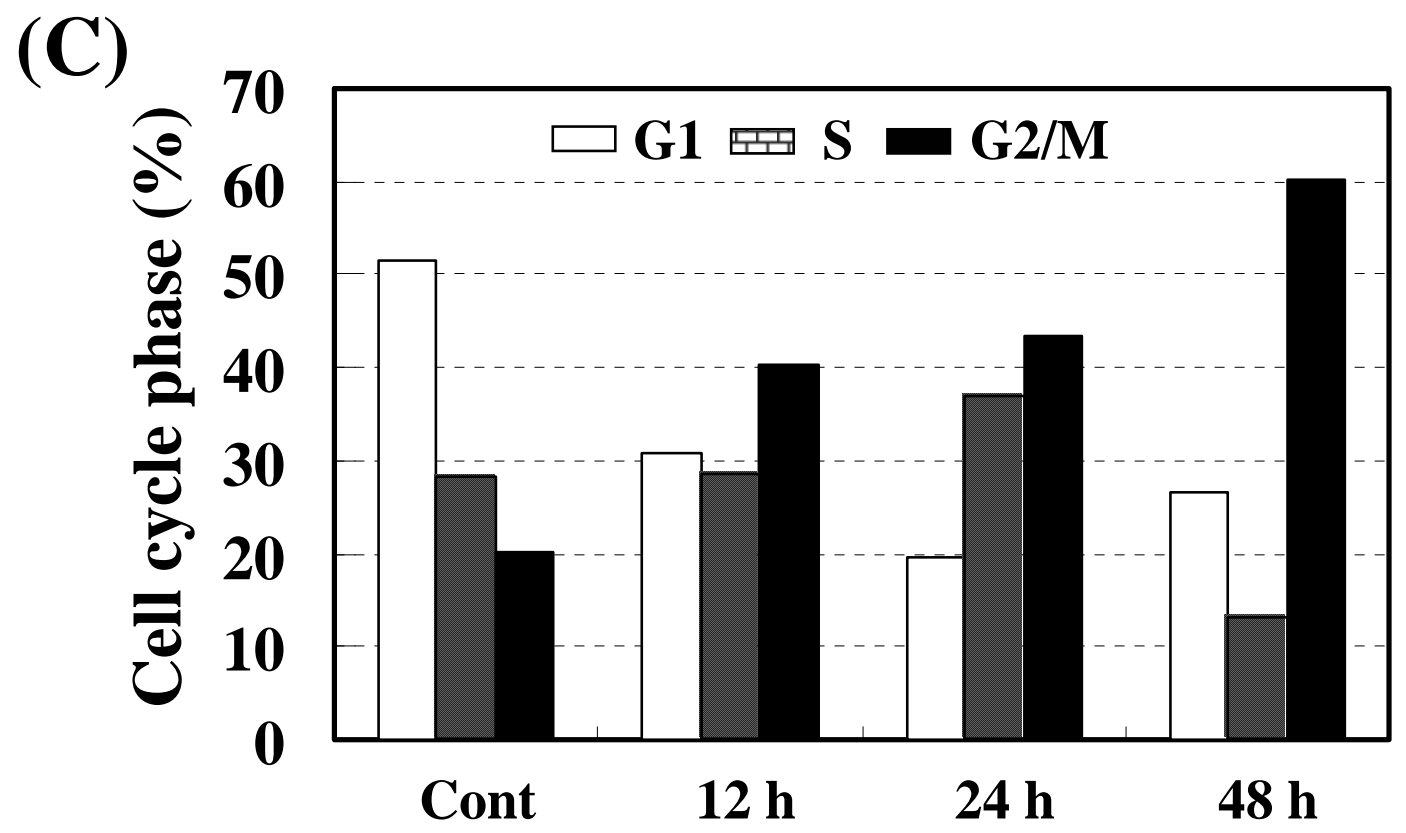


Figure 3. Seong Gyu Ko, et al
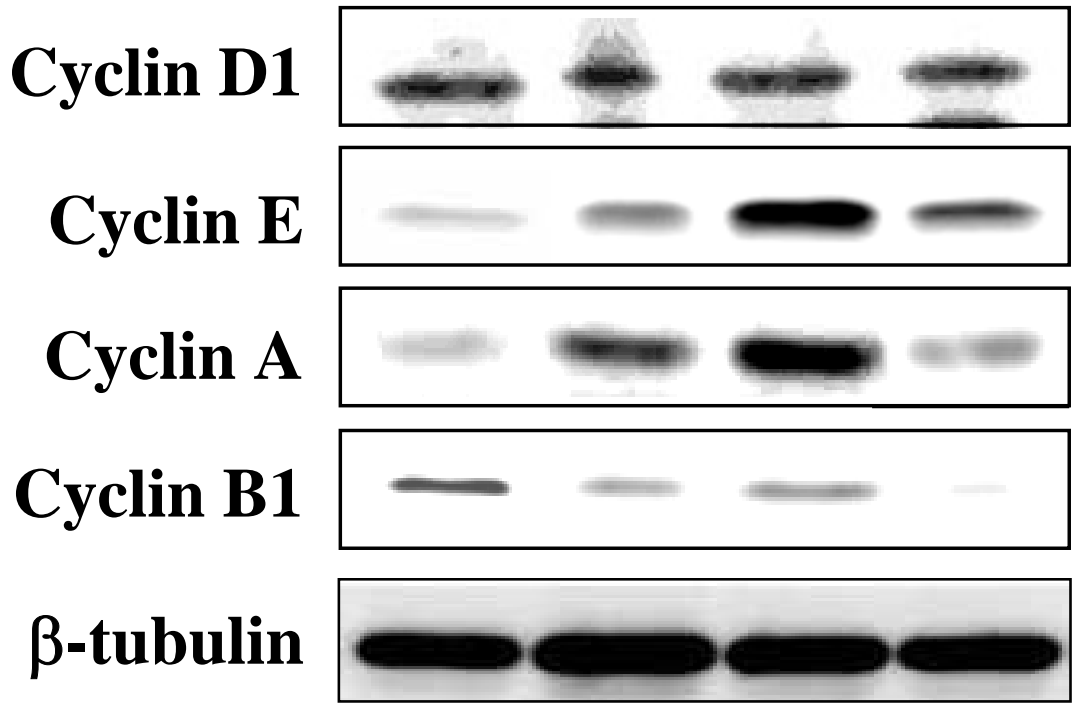

$\begin{array}{ccccc}\mathrm{SA}(100 \mu \mathrm{g} / \mathrm{ml}) & - & + & + & + \\ \text { Treatment (h) } & 0 & 12 & 24 & 48\end{array}$


Figure 4. Seong Gyu Ko, et al

(A)

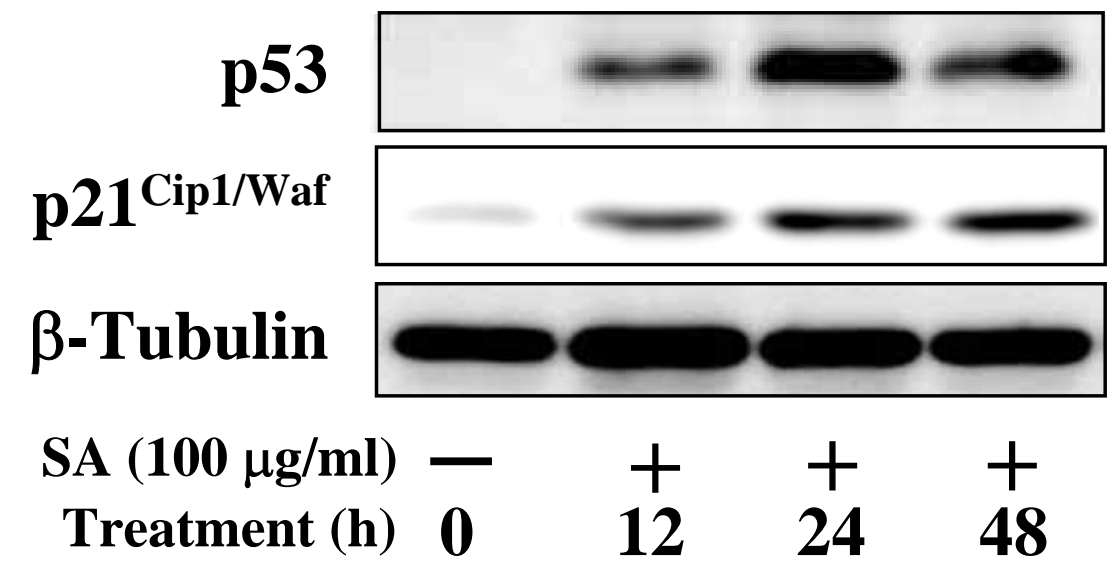

(B)

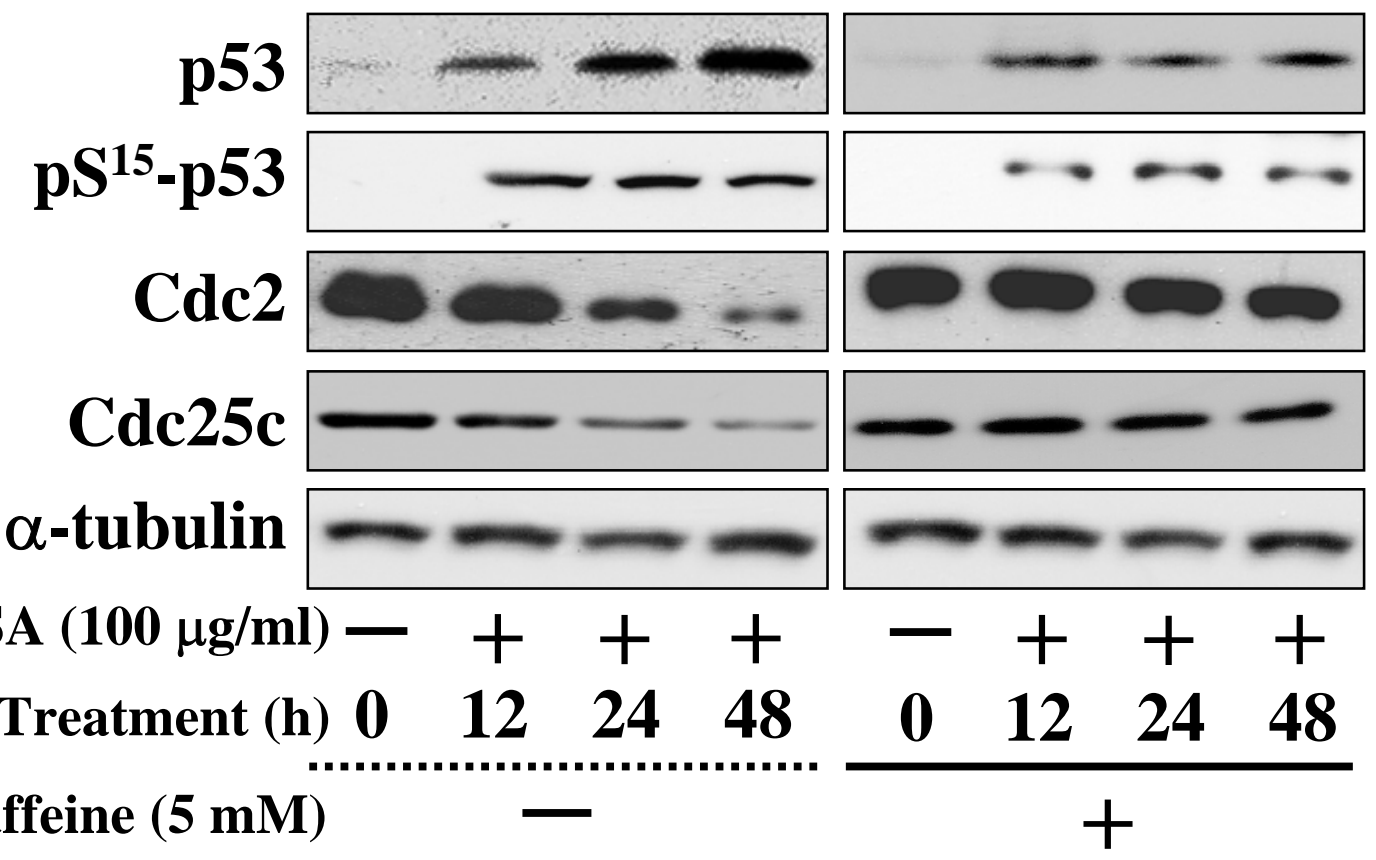


Figure 5. Seong Gyu Ko, et al

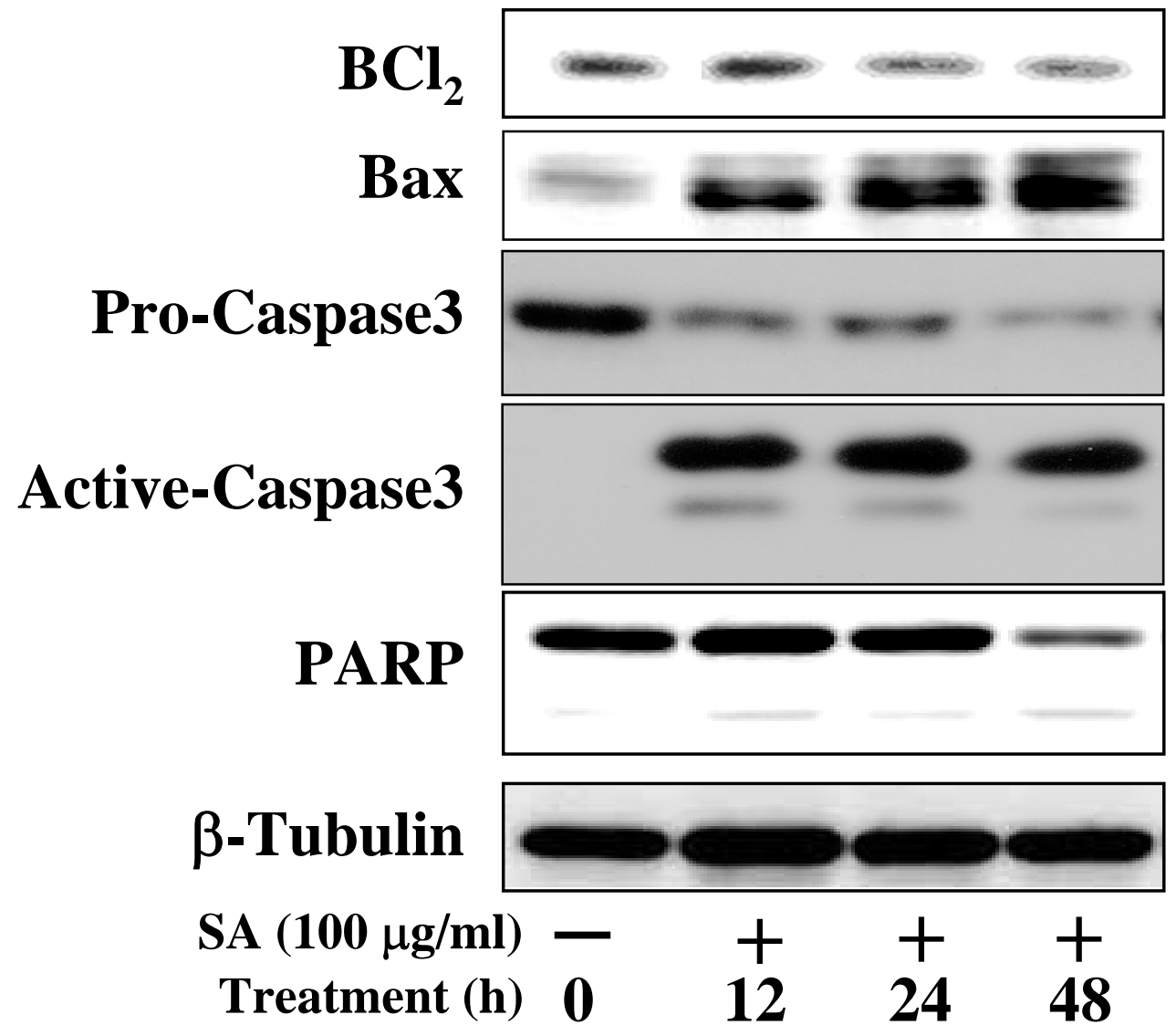

